\title{
EL IMPACTO SOCIAL DE LAS TRANSFORMACIONES URBANÍSTICAS: RESISTENCIAS VECINALES A LA CONSTRUCCIÓN DE UN SHOPPING CENTER EN UN BARRIO DE LA CIUDAD DE BUENOS AIRES ${ }^{1}$
}

\section{THE SOCIAL IMPACT OF URBAN TRANSFORMATIONS: NEIGHBORHOOD RESISTANCE} TO THE SETTING UP OF A MALL IN BUENOS AIRES CITY

\author{
Juliana Marcús ${ }^{2}$
}

\section{Resumen}

Este trabajo presenta algunos resultados de una investigación en curso sobre los procesos de mercantilización de la Ciudad de Buenos Aires y su incidencia en los usos legítimos e ilegítimos del espacio urbano. El artículo se centra en el análisis del impacto social de las transformaciones urbanísticas a partir de las reacciones, los mecanismos de participación y las resistencias vecinales y corporativas a la instalación de un shopping center en el barrio de Caballito, un área central de la Ciudad de Buenos Aires. La metodología de investigación consistió en observaciones etnográficas y en la realización y el análisis de entrevistas en profundidad a los diversos actores que participaron en la esfera pública con el fin de suspender, retrasar y denunciar la habilitación y la construcción del centro comercial.

Palabras clave: Producción del espacio urbano - Mercantilización de la ciudad - Transformaciones urbanísticas - Asociaciones vecinales - Shopping center

\begin{abstract}
This work shows some results of an existing research on commodification processes in the city of Buenos Aires as well as its impact on the legitimate and illegitimate use of urban space. The article focus on the analysis of social impact of urban transformations as from the reactions, participation mechanisms and neighborhood and corporate resistance to the setting up of a mall in Caballito -a central neighborhood in Buenos Aires city. The research methodology consisted of ethnographic observations and thorough analysis of interviews to different actors who manifested their aim of suspending, delaying and questioning publicly the approval of the project.
\end{abstract}

Keywords: Production of urban space - Commodification of the city - Urban transformations Neighborhood associations - Mall

\footnotetext{
${ }^{1}$ Una versión preliminar de este trabajo fue presentada en el VIII Seminario Internacional de Investigación en Urbanismo, Universidad de la República, Montevideo, Uruguay, 8 y 9 de junio de 2015.

2 Doctora en Ciencias Sociales y Licenciada en Sociología por la Universidad de Buenos Aires. Investigadora Asistente del Consejo Nacional de Investigaciones Científicas y Técnicas e Investigadora del Instituto de Investigaciones Gino Germani. Se desempeña como Profesora Titular del seminario de investigación "Vida urbana y producción social del espacio: usos y apropiaciones diferenciales de la ciudad", Carrera de Sociología, UBA. Ha publicado capítulos de libros en Chile, México y Argentina y artículos en revistas nacionales e internacionales: Estudios Demográficos y Urbanos (COLMEX-México), Scripta Nova (Barcelona), Revista AREA (Argentina), Inguruak (España), Ciudades (México), Territorios (Colombia), Intersticios (España), Población de Buenos Aires (Argentina), Cuaderno Urbano (Argentina), Revista Argentina de Sociología (Argentina).E-mail: julimarcus@gmail.com
} 


\section{INTRODUCCIÓN}

Este trabajo presenta algunos hallazgos de una investigación en curso sobre los procesos de mercantilización de la Ciudad de Buenos Aires y su incidencia en los usos legítimos e ilegítimos del espacio urbano. El artículo se centra en el análisis del impacto social de las transformaciones urbanísticas a partir de las reacciones, los mecanismos de participación y las resistencias vecinales y corporativas a la instalación de un shopping center ${ }^{3}$ en el barrio de Caballito, un área central de la Ciudad de Buenos Aires.

El trabajo se divide en tres secciones. En la primera se desarrolla el contexto más amplio en el cual se enmarca la construcción del nuevo centro comercial, un contexto de neoliberalización del espacio donde la producción de la ciudad se piensa en términos mercantiles. En el segundo apartado se aborda el conflicto en torno a la construcción de un nuevo shopping center en el barrio y los diversos actores sociales que intervienen en el proceso: el emprendedor inmobiliario Inversiones y Representaciones S.A. (IRSA) que desde 1999 es propietario de los terrenos aledaños al Club Ferro Carril Oeste donde proyecta construir el centro comercial desde 2008, el Gobierno de la Ciudad de Buenos Aires (GCBA) que en los últimos años ha impulsado un proyecto de ley que modifica las normas de planeamiento urbano para que la zona donde se encuentran emplazados dichos terrenos se convierta en área comercial, y las asociaciones vecinales, los residentes no nucleados, los centros culturales y los comerciantes que intervienen en este proceso desde la resistencia. En la tercera y última parte se estudia el impacto social de las transformaciones urbanísticas en el barrio y en la vida cotidiana de los residentes y se analizan las reacciones de las asociaciones vecinales, las intervenciones en la esfera pública, los mecanismos de participación, los reclamos y las propuestas.

¿De qué modo la dinámica urbana ha interpelado a los vecinos nucleados en asociaciones para que se movilicen en contra de las transformaciones del barrio de Caballito asociadas no sólo al nuevo centro comercial sino también a las torres en altura? ¿Cómo impactan estas transformaciones en el uso, las prácticas cotidianas y los estilos de vida que modulan el habitar de los residentes de Caballito? A lo largo del presente trabajo veremos cómo la ciudad se presenta como "espacio disputado" poniendo en relieve los conflictos por el uso que habrá de darse al

\footnotetext{
${ }^{3}$ Los shopping center como artefactos urbanos aparecen por primera vez en el paisaje porteño durante la década del '90. Si bien en un primer momento fueron consagrados como espacios de compra de bienes y servicios suntuosos y recibidos de forma celebratoria como símbolo de una presunta modernidad urbana, rápidamente fueron cuestionados en ámbitos públicos y académicos por su carácter excluyente, privatizador y banalizador del espacio público.
} 
espacio entre los diferentes actores: Estado local, desarrolladores inmobiliarios, urbanistas, asociaciones vecinales, centros culturales, etc.

El trabajo de campo fue realizado entre octubre de 2013 y octubre de 2014 en el marco de dos proyectos de investigación financiados por la Secretaría de Ciencia y Técnica de la Universidad de Buenos Aires ${ }^{4}$ y consistió en observaciones etnográficas, registro fotográfico y la realización y análisis de entrevistas en profundidad a los diversos actores que participaron en la esfera pública con el fin de suspender, retrasar y denunciar la habilitación y la construcción del centro comercial. Asimismo se analizaron diversos artículos periodísticos publicados durante el período que abarcó el conflicto con el objetivo de analizar el problema de investigación desde una perspectiva diacrónica.

\section{URBANISMO NEOLIBERAL Y PRODUCCIÓN SOCIAL DEL ESPACIO}

La idea principal del urbanismo neoliberal es que las ciudades funcionen como empresas orientadas hacia el rendimiento y la generación de plusvalía. En este sentido, las acciones políticas y económicas llevadas a cabo bajo esta lógica persiguen la extracción de plusvalía urbana. Ahora bien, las plusvalías urbanas se generan no sólo a partir de mecanismos puramente mercantiles, sino que requieren de regulaciones políticas, narrativas legitimadoras y la intervención de agentes externos al mercado (Franquesa, 2007). En este contexto, los gobiernos locales llegan a considerar como prioridad la creación de facilidades para la inversión privada lo que a su vez facilita la toma de posesión del suelo por parte de los capitales privados que en definitiva buscan aquellos escenarios con las menores trabas para operar.

¿Cómo se produce el espacio urbano en un contexto capitalista? Para responder este interrogante nos basamos en la teoría de Henri Lefebvre (2013) [1974] sobre la producción social del espacio elaborada a partir de una división tríadica compuesta por las prácticas espaciales, las representaciones del espacio y los espacios de representación. A cada una de estas dimensiones corresponde un tipo de espacio, respectivamente: el espacio percibido, el espacio concebido y el espacio vivido. La práctica espacial se corresponde con el espacio percibido, el más cercano a la vida cotidiana y a los usos de los lugares que vinculan la realidad cotidiana y la realidad urbana. En

\footnotetext{
${ }^{4}$ Me refiero a los Proyectos UBACYT "Discriminación social en la ciudad. La incidencia de las políticas habitacionales en los procesos de jerarquización del espacio urbano" (2012-2014) y "La incidencia de los procesos de mercantilización de la ciudad en los usos legítimos e ilegítimos del espacio urbano" (2014-2017) que dirijo en el Instituto de Investigaciones Gino Germani (FSOC-UBA). El análisis que presento en este artículo es el resultado de valiosos debates compartidos con mis compañeros y colegas de los Proyectos UBACYT durante nuestras reuniones periódicas de investigación. A ellos, un especial agradecimiento.
} 
el contexto de una ciudad, la práctica espacial remite a lo que ocurre en las calles y en las plazas, los usos que éstas reciben por parte de habitantes e itinerantes, los modos en que el transeúnte recorre, circula, transita por la ciudad. Las representaciones del espacio se corresponden con el espacio concebido, el espacio provisto por el Estado, los científicos, los tecnócratas, los arquitectos, los planificadores y los urbanistas. "Es el espacio dominante en cualquier sociedad (o modo de producción)" (Lefebvre, 2013: 97). En cuanto a los espacios de representación, son los espacios vividos, espacios de la imaginación y de lo simbólico dentro de una existencia material. "El espacio de representación se vive, se habla (...) Contiene los lugares de la pasión y de la acción, los de las situaciones vividas y, por consiguiente, implica inmediatamente al tiempo" (Lefebvre, 2013: 100). En este espacio se inspiran las deserciones y desobediencias ciudadanas (Delgado, 2013). Si bien Lefebvre plantea que la tensión, las pugnas y las resistencias permanentes entre estos tres espacios parecerían dirimirse en el contexto de la sociedad capitalista en favor del espacio concebido, veremos en el último apartado de este trabajo que a partir de las resistencias y movilizaciones vecinales es posible pensar en una lucha por imponer el espacio vivido sobre el espacio concebido.

En un contexto de neoliberalización, el espacio urbano no sólo se vuelve una mercancía caracterizada por su valor de cambio, es también un espacio de vida caracterizado por sus valores de uso. Ahora bien, como señala Franquesa (2013), se produce una tensión entre ambos: de un lado el capital inmobiliario, la planificación urbanística y, en ocasiones, la administración local de la ciudad intentan ajustar las prácticas vecinales a las exigencias del valor de cambio, o, en términos lefebvrianos, se intenta ajustar el espacio percibido y vivido al espacio concebido. Del otro, determinados valores de uso que organizan la vida vecinal, como el reclamo por más espacios verdes en el barrio de Caballito y con ello las resistencias a la construcción de un nuevo shopping center y nuevas construcciones en altura, se alzan como un desafío ante la lógica de la acumulación y la plusvalía urbana.

En este marco, también denominado "lógica espacial de la neoliberalización" (Franquesa, 2007), hemos analizado en otro trabajo (Marcús, Aquino, Benitez, Felice y Marquez, 2014), los procesos de "vaciar y llenar" (Franquesa, 2007, 2013) y de "destrucción creativa" (Schumpeter, 1962; Harvey, 2008, 2013) llevados a cabo en los ex-terrenos ferroviarios del barrio de Caballito y los predios aledaños que incluyen el terreno donde se planea construir el centro comercial, entendiendo por estos procesos la destrucción del valor económico de un espacio para una posterior obtención de beneficios mediante la revalorización inmobiliaria. Estos terrenos, 
aparentemente disponibles y vacantes, son considerados "áreas de oportunidad" (Cuenya, 2011), espacios vacíos desde el punto de vista de su valorización y rentabilidad. Una de nuestras principales hipótesis es que estos procesos -en los que participan inversores inmobiliarios, planificadores y desarrolladores urbanos, gobiernos local y nacional- regulan y disciplinan los usos del espacio urbano e intervienen en lo que David Harvey (2013) denomina el "derecho a lo urbano", es decir, el derecho a la apropiación espontánea del espacio público.

\section{DE LA “DESVALORIZACIÓN" DE LOS EX-TERRENOS FERROVIARIOS AL SHOPPING CENTER}

"La mercantilización y comercialización de todo es de hecho una de las marcas distintivas de nuestra época". (David Harvey, 2013)

Los terrenos del playón ferroviario (Imagen 2) ubicados en el barrio porteño de Caballito ${ }^{5}$ (Imagen 1) poseen una extensión de 1,27 km. de longitud y un ancho de $270 \mathrm{~m}$., pertenecen al Estado Nacional y son administrados por el Organismo Nacional Administrador de Bienes del Estado (ONABE). El Gobierno de la Ciudad de Buenos Aires (GCBA) es quien tiene la potestad normativa para esos predios y puede fijar el perfil de las operaciones posibles a realizar en ellos. Tal como hemos descripto en un trabajo anterior (Marcús et al., 2014: 78), hasta principios de la década del '90 los terrenos ferroviarios fueron utilizados como playa de maniobras y depósito de vagones. Luego, a partir de la profundización del modelo neoliberal y la consecuente crisis del ferrocarril, fueron abandonados durante más de 20 años llevándose a cabo un lento proceso de vaciamiento urbano. Durante ese tiempo, diferentes organizaciones de la sociedad civil se movilizaron para que allí se desarrollen espacios verdes y se lleve adelante el prometido Parque del Bicentenario. Ahora bien, estos terrenos también fueron escenario de un proceso de vaciamiento explícito a partir del desalojo, ejecutado por autoridades del GCBA junto con efectivos de la Policía Federal en octubre de 2008, de dos recicladoras de cartones ubicadas en las cercanías del Puente Caballito que utilizaban el lugar como sede de trabajo, y un asentamiento de 200 familias que participaban de la actividad.

\footnotetext{
${ }^{5}$ El barrio de Caballito pertenece a la Comuna $\mathrm{N}^{\circ} 6$ de la Ciudad de Buenos Aires. Es un barrio central de la ciudad con buen acceso a equipamientos y servicios. En el imaginario social porteño así como en la propia identificación de los residentes, el barrio de Caballito es un "típico" barrio de clase media. En efecto, los datos de la Encuesta Anual de Hogares 2014 muestran que el 81,5\% tiene el nivel secundario completo y que el ingreso familiar promedio es de 14.074 pesos argentinos mensuales, colocándose en el octavo lugar respecto a las Comunas de mayores ingresos de la ciudad.
} 
Imagen 1. Barrio de Caballito, Comuna 6. Ciudad de Buenos Aires, 2015

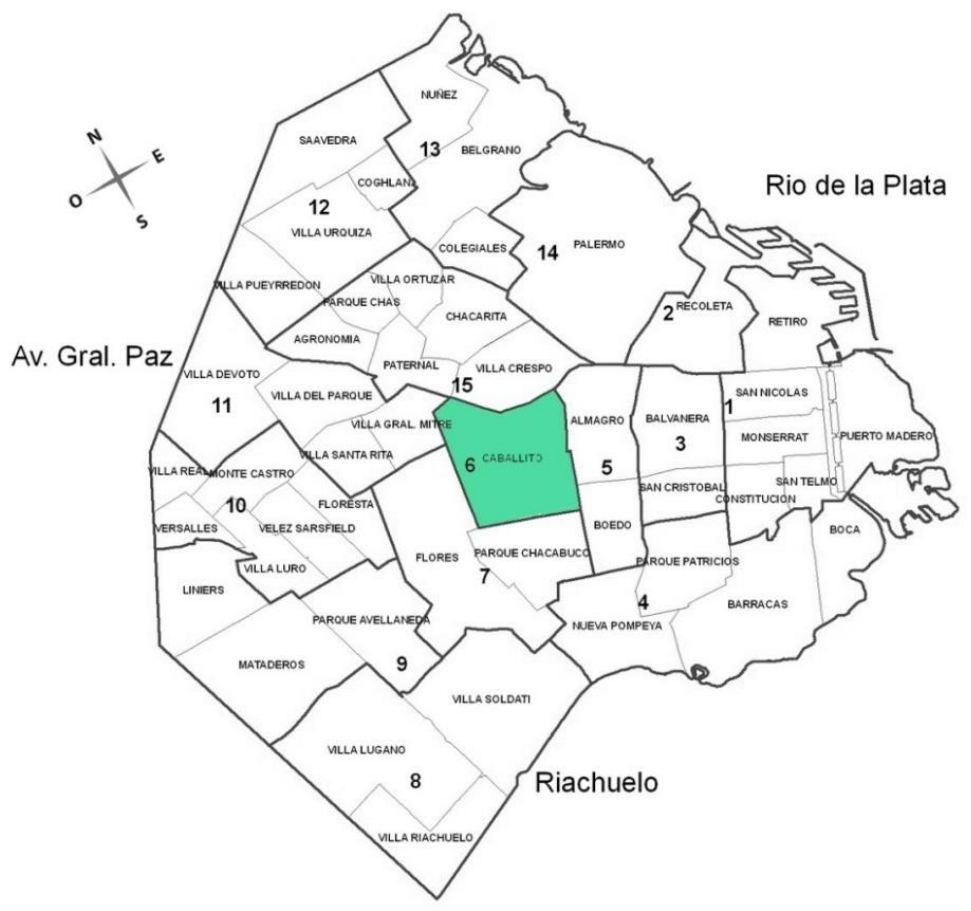

Fuente: Elaboración propia en base a datos del Gobierno de la Ciudad de Buenos Aires

Imagen 2. Ex-terrenos ferroviarios de Caballito y predio donde se proyecta construir el shopping center, Ciudad de Buenos Aires.

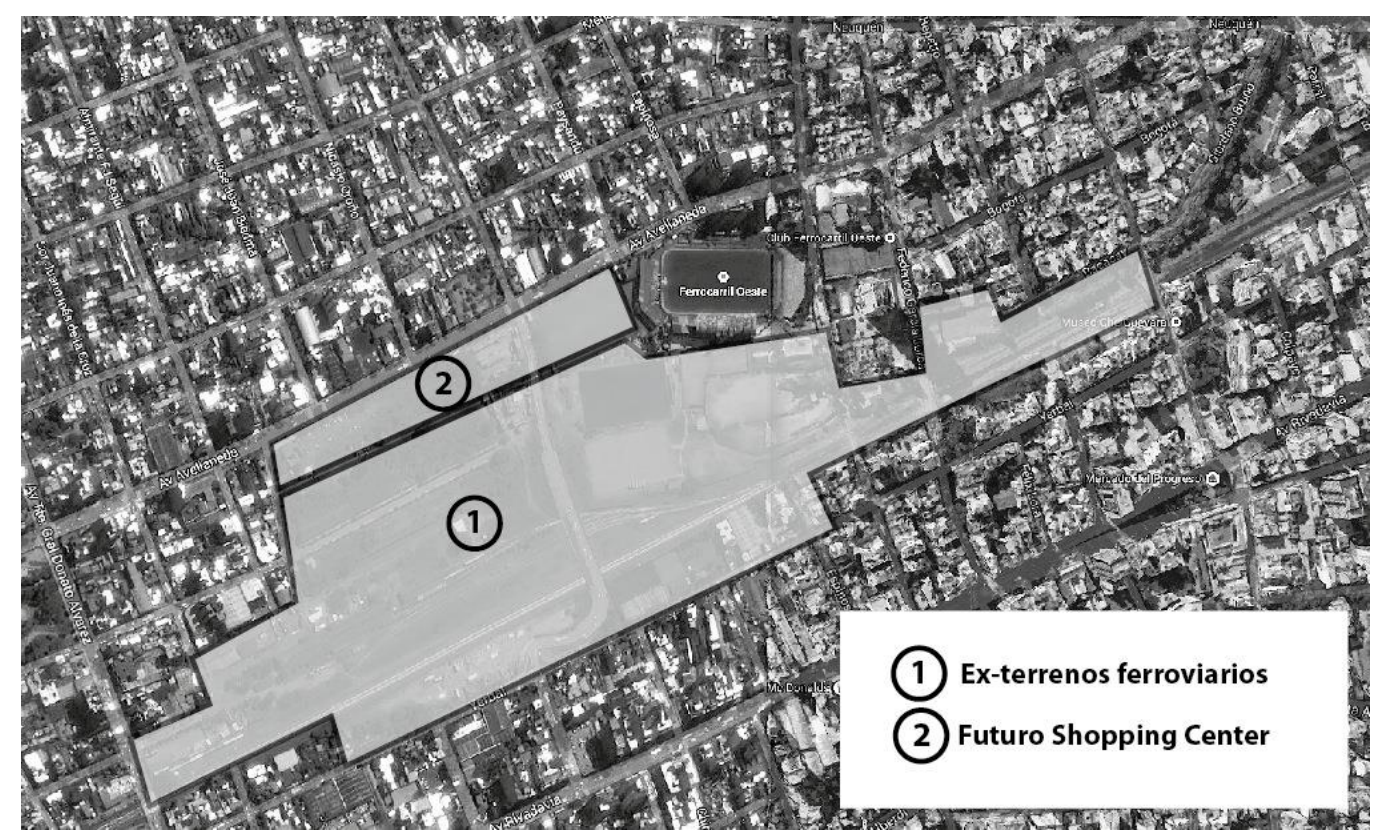

Fuente: Elaboración propia a partir del Google Earth, 2015 
En el trabajo de investigación realizado, observamos que "producto de este vaciamiento y de la destrucción sufrida durante más de 20 años, los ex-terrenos ferroviarios configuran actualmente un área que ha quedado postergada, con excelente accesibilidad y posibilidad de transformación urbanística y valorización, con un bajo valor de partida como consecuencia de su abandono y deterioro y con una gran capacidad para alcanzar altos valores a partir de su refuncionalización y transformación física" (Marcús et al., 2014: 78-79). Desde la lógica del capital, estos terrenos "abandonados" resultan improductivos, no son rentables y por lo tanto deben ser recuperados para su "puesta en valor" y la extracción de plusvalías urbanas. En septiembre de 2012 se desafectaron los inmuebles del servicio ferroviario con el objetivo de comenzar con el proceso de "llenado" de dichos terrenos. Para llevarlo a cabo, en enero de 2013 la Administración Nacional de Seguridad Social (ANSES) y la Sociedad Central de Arquitectos llamaron a un Concurso Nacional para desarrollar el proyecto urbano denominado Nuevo Caballito, un emprendimiento inmobiliario que constaría de construcciones para uso residencial que no podrían superar los ocho pisos de altura y que debía seguir los lineamientos de la Ley $4477^{6} .7$

Aparece esta decisión [de la convocatoria al Concurso] del Gobierno Nacional en tierras que son de su propiedad, pero sin que previamente haya habido un plan general de la Ciudad que incluya y que discuta el destino de estas tierras dentro del conjunto. No hubo un proceso de participación y consulta ciudadana tomando todos los estamentos que la propia Constitución de la Ciudad de Buenos Aires define. No hubo una discusión previa sobre cuál era la norma urbanística que debía aplicarse al lugar (...). (Integrante de la Asociación Vecinal SOS Caballito).

Como veremos en el próximo apartado, las resistencias vecinales en respuesta a los cambios vividos en el barrio pueden considerarse reacciones ante la ausencia de consulta por parte de los planificadores. Es decir, no se ha tenido en cuenta la voz de los habitantes ni se han incentivado mecanismos participativos en la toma de decisiones sobre el barrio que se desea tener y habitar. Esta situación genera que el barrio se presente como ámbito de disputa entre las asociaciones vecinales, el Estado y los desarrolladores privados.

El predio donde se proyecta construir el shopping center se encuentra próximo a los terrenos que fueron afectados por el concurso antes mencionado para su urbanización (Imagen 3). Estas tierras fiscales fueron cedidas en la década del '80 por el Estado Nacional al Club Ferro Carril

\footnotetext{
${ }^{6}$ La Ley 4477, sancionada en la Legislatura Porteña en diciembre de 2012, plantea que el uso residencial no podrá superar el 35\% del total de la superficie del predio. El 65\% restante debe destinarse a uso público.

${ }^{7}$ Para profundizar en el proceso de llenado y el proyecto inmobiliario ganador ver Marcús et al., 2014: 81-82.
} 
Oeste $^{8}$ para uso deportivo. El titular de las mismas continuaba siendo el Estado pero a partir de aquella transferencia el usufructo le correspondía al club. Según los socios del club "la institución deportiva presuntamente los vendió en 1998 sin ser la dueña" ${ }^{\prime \prime}$, es decir, en el certificado de dominio catastral sólo figuran dos propietarios entre 1958 y la actualidad: el Estado y a partir del 20 de enero de 1999, Alto Palermo S.A., subsidiaria del desarrollador inmobiliario Inversiones y Representaciones S.A. (IRSA) ${ }^{10}$, principal propietaria de centros comerciales de la ciudad. El Club Ferro no figura en ese certificado de modo que se trató de una venta irregular de tierras fiscales que pasaron a formar parte del patrimonio de IRSA. ${ }^{11}$

Imagen 3. Primer premio del Concurso Nacional para el desarrollo del Plan Maestro Playa Ferroviaria Caballito

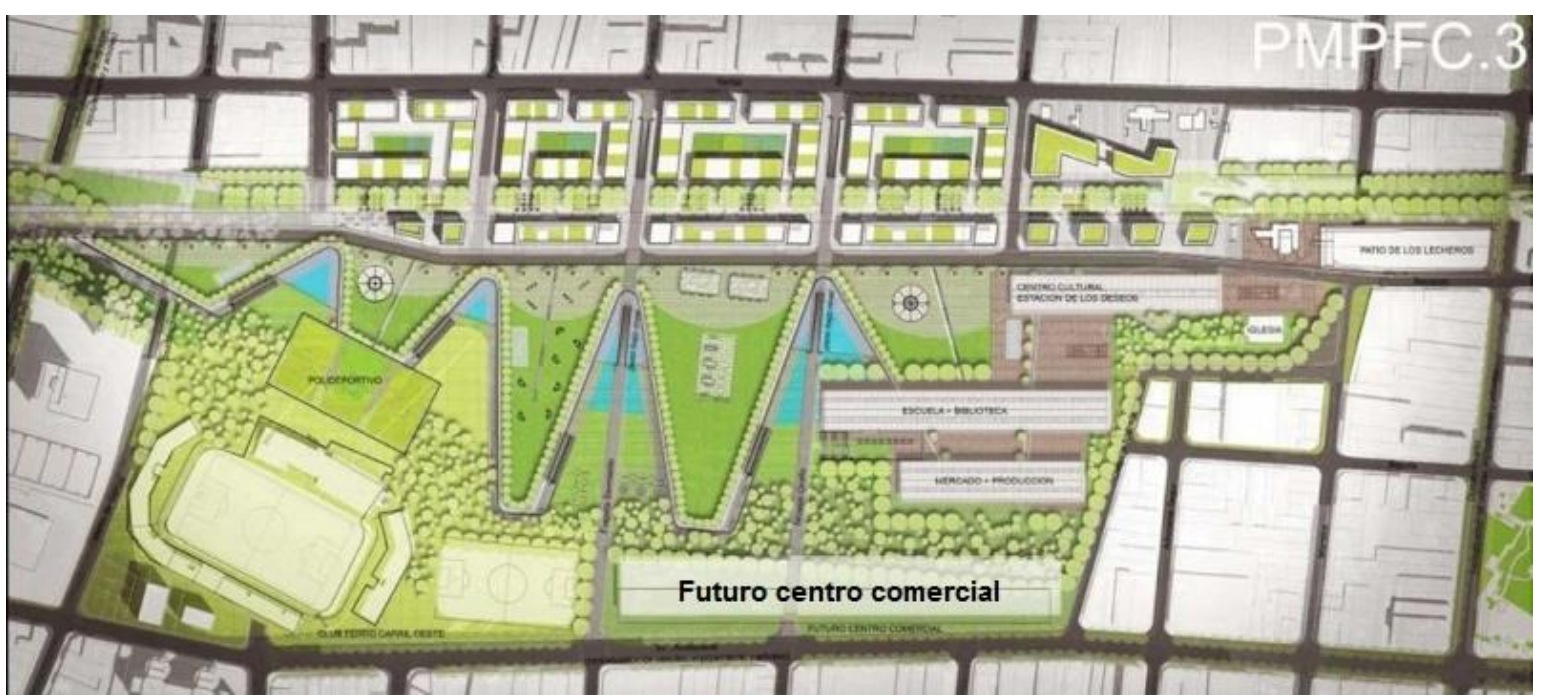

Fuente: Sociedad Central de Arquitectos, 2013.

Los terrenos aledaños al Club Ferro donde IRSA planea construir un nuevo centro comercial se encuentran aparentemente abandonados y utilizados como depósito de contenedores. Con respecto al aparente abandono de los terrenos, los vecinos entrevistados decían:

Los que están a favor del shopping dicen 'la zona está abandonada'. La verdad que es cierto, pero no dicen que es

\footnotetext{
${ }^{8}$ El Club Ferro Carril Oeste, fundado en 1904, es una institución histórica en el barrio de Caballito que otorga identidad y sentido de pertenencia a sus residentes.

9Fuente: "Un shopping nacido de la ilegalidad", (Página/12, 02/12/13) [http://www.pagina12.com.ar/diario/sociedad/3-234779-2013-12-02.html], consulta: 27/12/14.

${ }^{10}$ Para profundizar sobre la historia del Grupo IRSA, su estrategia empresarial en la ciudad y su relación con las diferentes agencias del Estado, ver Socoloff, 2014.

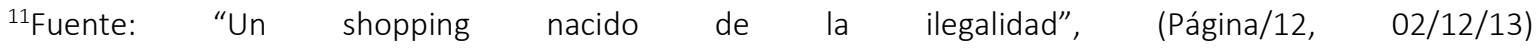
[http://www.pagina12.com.ar/diario/sociedad/3-234779-2013-12-02.html], consulta: 27/12/14.
} 
deliberado el abandono, porque nosotros tenemos proyectos desde el año '94 (...) Hay pedidos recurrentes de muchos años de historia pidiendo que esto se transforme en parque. El abandono es el interés que justifica que después lo vendas porque decís: 'peor que esto no hay nada, hagamos algo. Venga el progreso, traigan un shopping'. Digo, es una cosa inteligente hecha por ellos y en complicidad con muchos de los que integran los órganos de poder, ¿no? Porque evidentemente es IRSA el que también está detrás de todo esto proponiendo favorecerse con este negocio, ¿no?

(Integrante de la Asociación Vecinal SOS Caballito).

Toda esa parte está como abandonada, pero es una desidia para mí, que yo lo discuto y a veces me hacen callar, es una desidia programada, programada para que los vecinos nos quejemos de los delincuentes, los borrachos y el abandono, ¿para qué? para justificar este proyecto.

(Integrante Movimiento Identidad Caballito).

Entrevistado: Ellos [IRSA] cuando hablan de ese espacio [los exterrenos ferroviarios], hablan de un espacio abandonado Entrevistadora: ¿Qué incluye el espacio abandonado?

Entrevistado: Nosotros, por ejemplo, nosotros somos parte del abandono, no somos gente ni nada, somos un pedazo de abandono. Cuando en realidad lo único que hicimos es hacer lo que tendría que haber hecho el Estado, recuperar una cuestión que es de características históricas.

(Integrante del Centro Cultural Estación de los Deseos, espacio de valor patrimonial).

Como vimos en el apartado anterior, se trataría de un claro ejemplo de "destrucción creativa" sostenida en el rol heroico que asume, en este caso, el desarrollador inmobiliario IRSA quien viene a "salvar" aquellos terrenos deteriorados producto del abandono deliberado a partir de la idea de construir un centro comercial que revalorizaría y revitalizaría la zona. Con esta acción se oculta e invisibiliza el proceso de "destrucción" y se ilumina y destaca el proceso de "creación" o "llenado".

IRSA planea invertir 300 millones de dólares en la construcción de un shopping center de $70.000 \mathrm{~m} 2$ y 35 metros de alto que demandaría dos años en edificarse. ${ }^{12}$ Ahora bien, el grupo inversor pretende emplazar el nuevo shopping en un predio cuya zonificación es de carácter residencial. Para ello, el GCBA ha impulsado un proyecto de ley que modifica las normas de planeamiento urbano para que dicha zona se convierta en área comercial. En diciembre de 2014 el proyecto fue tratado por cuarta vez en la Legislatura porteña y una vez más no obtuvo la mayoría

12 Fuente: "Por cuarto año, se frena el proyecto del shopping en Caballito", (Clarín, 10/12/14) [http://www.clarin.com/ciudades/Shopping_Caballito-IRSA-rezonificacion_0_1264073792.html], consulta: 27/12/14. 
necesaria para ser aprobado. Según las asociaciones vecinales entrevistadas, desde la Comuna de Caballito se denunció que la Legislatura porteña violó el Artículo 63 de la Constitución de la Ciudad de Buenos Aires debido a que no convocó a una Audiencia Pública para el tratamiento legislativo y tampoco realizó una consulta popular en la Comuna para que sean los vecinos del barrio quienes decidan sobre la conveniencia o no del proyecto. Con este tipo de acciones, tanto IRSA como el GCBA intentan transformar el marco normativo de los principales instrumentos de regulación del suelo. En definitiva, estos procesos de mercantilización de la ciudad pretenden transformarla en "negocio". Los inversores inmobiliarios, los de la construcción y los gobiernos a su servicio entienden que las ciudades deben convertirse en una mercancía de la que es posible obtener beneficios. En un contexto de neoliberalismo urbano, el espacio concebido por el Estado, los planificadores y los inversores termina, tarde o temprano, convertido en espacio inmobiliario, es decir, en espacio para vender (Delgado, 2013).

Este gobierno va cotejando la desidia programada para que la gente nos quejemos y presentar su proyecto del gran shopping y de las grandes torres y se olvida de las necesidades, de la identidad barrial, necesidades de servicios públicos, porque al levantar el shopping... ¿ंTe imaginás un shopping, que te trae tanta gente? No son tontos, es una ubicación estratégica, en el centro de la ciudad. (Integrante de Movimiento Identidad Caballito)

En realidad se está haciendo una utilización especulativa y rentaria, crematística diría yo, de la tierra pública de la Ciudad de Buenos Aires, que se la utiliza como un recurso para la generación de dinero y no la búsqueda de satisfacción de las necesidades de las personas que viven en ella. (Integrante de la Asociación Vecinal Protocomuna Caballito)

\section{REPRESENTACIONES DEL ESPACIO VS. ESPACIOS DE REPRESENTACIÓN}

\section{El impacto del shopping en el barrio}

En este último apartado retomamos los interrogantes planteados en la Introducción de este trabajo: ¿De qué modo la dinámica urbana ha interpelado a los vecinos para que se movilicen en contra de las transformaciones del barrio de Caballito asociadas no sólo al nuevo centro comercial sino también a la construcción de torres en altura? ¿Cómo impactan estas transformaciones en el uso, las prácticas cotidianas y los estilos de vida que modulan el habitar de los residentes de Caballito? A continuación analizamos las reacciones, las intervenciones en la 
esfera pública, los mecanismos de participación, las resistencias, los reclamos y las acciones frente al conflicto de mercantilización del suelo urbano.

A partir de la construcción de torres en altura en el barrio de Caballito y el proyecto de edificar un nuevo centro comercial es posible mencionar los impactos de este tipo de emprendimientos en las dinámicas sociales barriales. Estas transformaciones urbanas generan múltiples conflictos que inciden en los modos del habitar, en el paisaje del barrio, en los hábitos y costumbres de sus habitantes y en la redefinición del significado social de un lugar. Según los residentes entrevistados, al igual que ocurre en otras zonas de la Ciudad de Buenos Aires ${ }^{13}$, vivir en un barrio que constantemente sufre transformaciones, es decir, que permanentemente se encuentra "en construcción" supone una contaminación visual (la pérdida de la identidad barrial frente a la edificación de enormes construcciones) y auditiva (los constantes ruidos de las obras en construcción y la congestión del tránsito). Las asociaciones vecinales entrevistadas destacan que el aumento de la actividad de la construcción de inmuebles ha producido en poco tiempo cambios profundos en el paisaje urbano. A partir de nuestros registros y observaciones de campo (Imágenes 4 y 5) pudimos constatar que las torres en altura terminan transformando el perfil inmobiliario de las cuadras del barrio de Caballito, uniformizando y homogeneizando la zona. Esto mismo sucede en otros barrios de la ciudad analizados en trabajos anteriores (Zarlenga y Marcús, 2014). En aquella oportunidad uno de los vecinos entrevistados nos decía: “(...) Los barrios que tienen identidad terminan perdiéndola, ni siquiera cambiándola por otra. Ya no decís: 'esta es una cuadra de Barracas', esta cuadra puede ser Barracas, puede ser Barrio Norte, puede ser cualquier lado (...) (Ibíd., p. 52).

Imagen 4. Construcciones en altura desde la cancha de fútbol del Club Ferro Carril Oeste

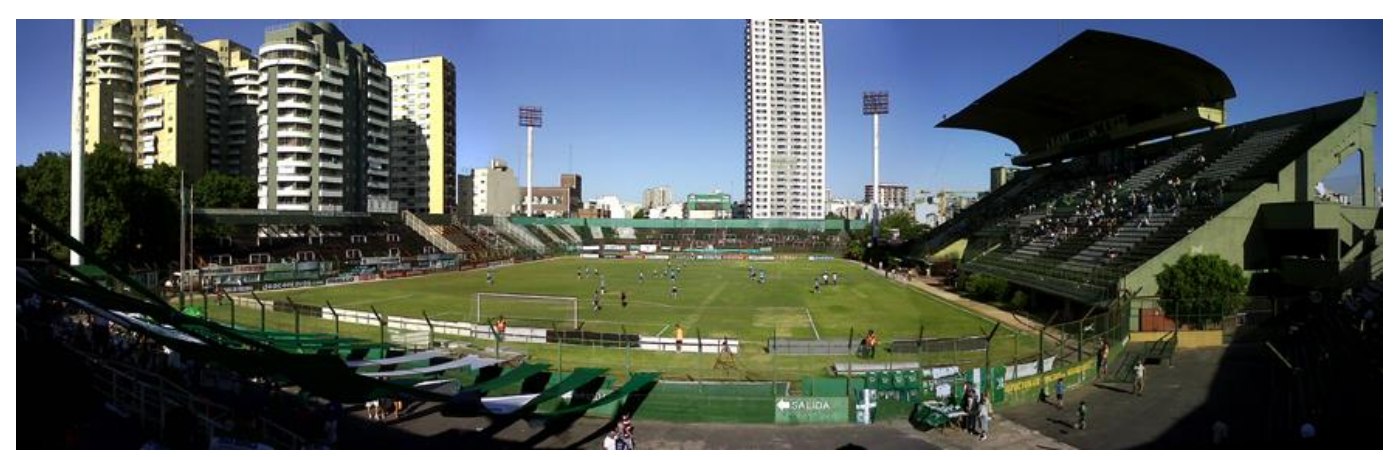

Fuente: Imagen extraída de www.gelp.org, consulta 20/09/2015.

13 Para profundizar en el impacto social de las transformaciones urbanas en los barrios del sur de la Ciudad de Buenos Aires, ver Zarlenga y Marcús, 2014. 
Imagen 5. Emprendimiento inmobiliario Torres Dosplaza ${ }^{14}$

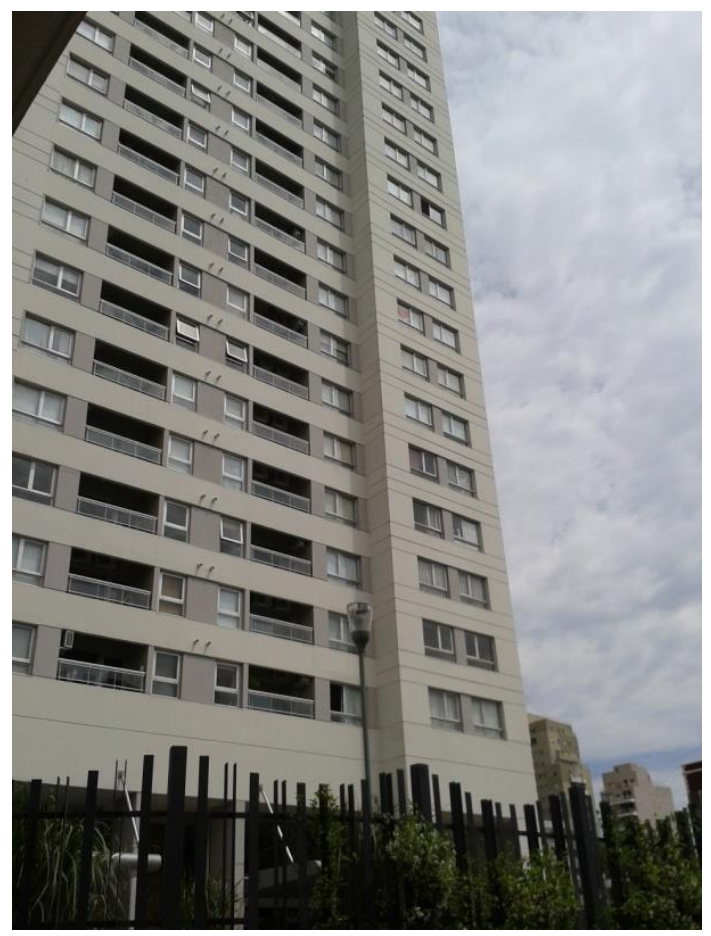

Fuente: Relevamiento fotográfico propio durante el trabajo de campo, Proyecto UBACyT, 2013.

Entendemos junto con David Harvey (2013) que el capital necesita homogeneizar los productos, en este caso las ciudades, para comercializarlos fácilmente. Pero al mismo tiempo, esa homogeneización excesiva conspira contra lo que hace especial y diferente a ese producto, perdiendo su monopolio de comercialización. De modo que para obtener rentas de monopolio existe una contradicción constante entre homogeneidad y heterogeneidad. Desde la lógica del capital, cuanto más fácilmente comercializables son las ciudades, cuanto más homogéneas son, menos únicas y distintivas resultan y por lo tanto ofrecen menos base para una renta de monopolio. Las transformaciones urbanas presentan la posibilidad de obtener una ganancia económica a costa de perder capital simbólico, o viceversa, perder oportunidades de hacer negocios pero obtener una mayor distinción social. Volveremos sobre esta idea más adelante.

Según datos estadísticos de la Secretaría de Planeamiento del GCBA ${ }^{15}$, entre 2001 y 2011 el aumento de la superficie residencial construida se concentró en el norte y centro de la ciudad

\footnotetext{
${ }^{14}$ El emprendimiento inmobiliario Torres Dosplaza se encuentra a pocas cuadras del Club Ferro Carril Oeste y del predio donde se proyecta construir el nuevo shopping center. En la imagen 4 se puede observar esta torre de 33 pisos de altura desde la cancha de fútbol del club.

${ }^{15}$ Fuente: Construcción en la Ciudad de Buenos Aires, 2001-2011. Secretaría de Planeamiento, Ministerio de Desarrollo Urbano, Ciudad de Buenos Aires.
} 
siendo Caballito el segundo barrio con mayor cantidad de m2 construidos (1.544.759). En primer lugar se ubica Palermo con 2.094.889 m2 construidos para la misma década. En la zona sur, donde el valor del suelo es mucho menor a los barrios centrales de la ciudad, se observan barrios con rangos de construcción por debajo de 260.000 m2 (Imagen 6). El aumento de la superficie residencial construida trajo aparejado, tanto en Caballito como en otros barrios del norte y centro de la ciudad, la revalorización y el aumento del precio del suelo lo cual produjo la captación de inversores privados para llevar adelante emprendimientos urbanos comerciales como shopping centers, restaurantes boutique, galerías de compras, entre otros.

Imagen 6. Total de la superficie residencial construida por barrio de la Ciudad de Buenos Aires.

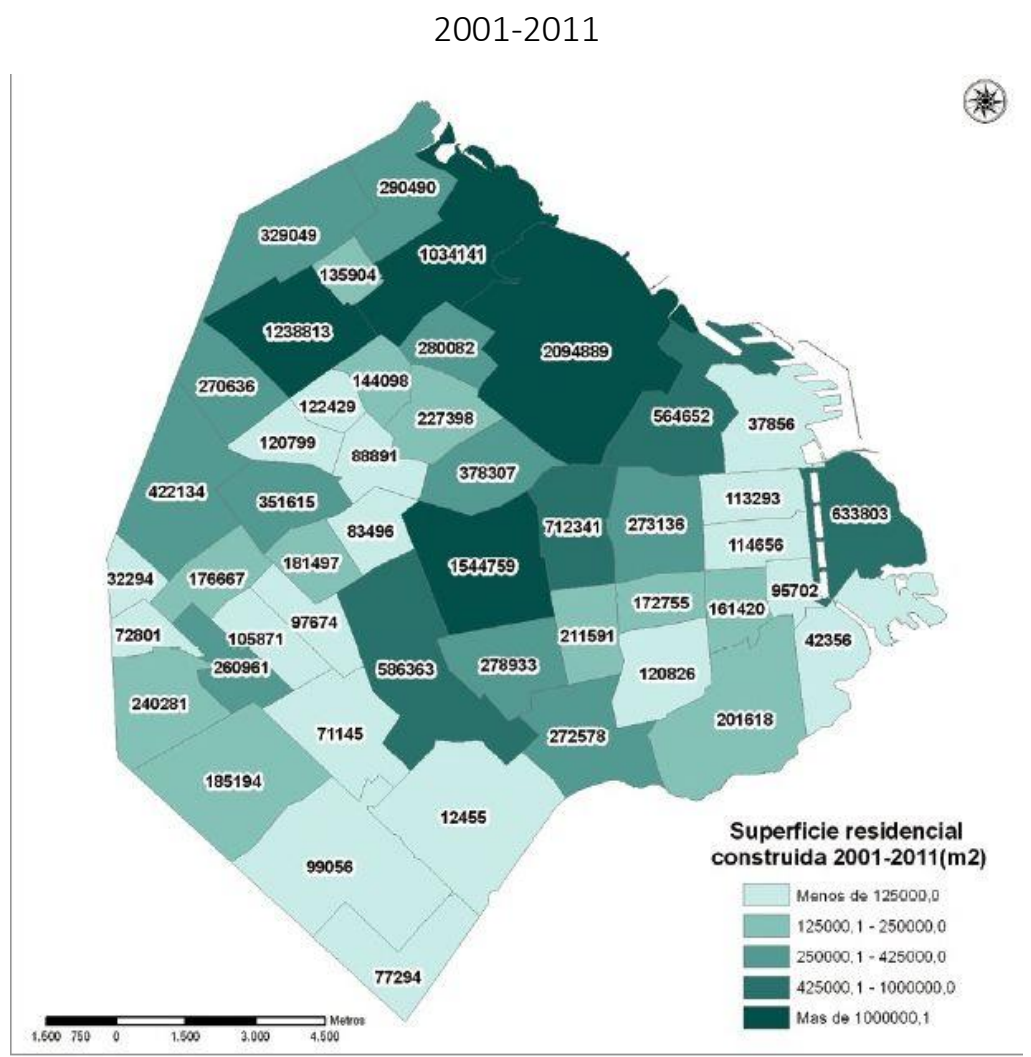

Fuente: Secretaría de Planeamiento, MDU. En base a DGEyC, GCBA.

Para IRSA y los vecinos a favor de la construcción del nuevo centro comercial| ${ }^{16}$, el shopping traerá más trabajo al barrio, seguridad, revitalización de la zona, revalorización de las propiedades e incluso más infraestructura pública. Las organizaciones barriales entrevistadas que se oponen

\footnotetext{
${ }^{16}$ Estos vecinos contribuyen a conformar un repertorio de narrativas legitimadoras (Franquesa, 2007) del accionar del "salvador", en este caso IRSA, que luego son recuperadas por éste para justificar el proyecto de edificación del shopping.
} 
mencionaron que el barrio no necesita otro centro comercial, menos aún de las dimensiones que tendrá el nuevo emprendimiento. De hecho, Caballito ya cuenta con un shopping center de 5.000 m2, con más de 80 locales comerciales inaugurado en octubre de 1994 cuyo dueño es el Grupo Inmobiliario Else (Chile), un mall de $15.000 \mathrm{~m} 2$ que incluye la cadena de cines Village construido en 2004 por el Grupo Sutton (Argentina) y, según la Cámara de Comercio de Caballito (CAMCAB), un total de 6.348 negocios en centros comerciales a cielo abierto. Además, según los vecinos, un nuevo shopping generaría un fuerte impacto ambiental que afectaría las distintas redes de servicios públicos sobre todo de agua y electricidad, congestionaría aún más el tránsito vehicular en la zona, traería contaminación auditiva, perjudicaría a los pequeños comerciantes que trabajan en el barrio y encarecería el valor del suelo. Estas consecuencias son experimentadas cotidianamente por los residentes del barrio de Saavedra, al norte de la Ciudad de Buenos Aires (Imagen 1) donde se encuentra el centro comercial Dot Baires, también del grupo IRSA. Los vecinos de ese barrio porteño sostienen que desde su apertura, en 2009, sufren fuertes inundaciones cuando llueve debido a que el shopping vierte sobre sus calles el agua que acumula.

El de la seguridad y el shopping es un mito que está difundido pero que realmente es mentira, porque en realidad por el hecho de que haya un shopping no hay una mayor presencia policial. O sea lo que prueba es que instalar un shopping no garantiza para nada la seguridad. Quizás adentro del shopping, no en las inmediaciones. Que va a revitalizar el área... va a elevar el valor del $\mathrm{m} 2$, yo no sé si eso va a revitalizarla. Va a ser una gran inversión para los que están acopiando terrenos baldíos en las cercanías esperando la construcción del shopping para poder subir el precio del $\mathrm{m} 2$ de venta a las construcciones que realicen. Para todos esos emprendedores inmobiliarios indudablemente les va a causar una gran ganancia, no sé si eso va a ser así para los vecinos que utilizan el barrio para vivir, no como una fuente de recursos.

(Integrante del a Asociación Vecinal Protocomuna Caballito)

El shopping de Caballito (...) va a dar problemas también con el tema de las napas, por lo tanto va a tener problema con las inundaciones. Segundo, va a tener una gran demanda eléctrica (...) Va a crear un caos de tránsito porque no hay conectividad norte-sur. La competencia desleal hacia el comerciante ¿por qué?, porque con la capacidad de compra que tiene un shopping no puede competir nunca un minorista, ni un mediano. Porque ellos compran en escala y además ellos fijan las condiciones de pago (...) El shopping tiene un solo dueño (...) IRSA no se acercó ni a los vecinos para explicar si iba a tener algún impacto ambiental, nada, IRSA no necesita consultar. Y además ni viven ahí, entonces les importa tres pepinos (...) El 
shopping no es para la ciudad y acá tenemos un shopping cada tres cuadras donde IRSA es dueño de la mayoría.

(Integrante de CAMCAB)

Ahora bien, ¿de qué modo se articulan las lógicas antes mencionadas sobre la homogeneización (construcción de shoppings y edificaciones en altura) y heterogeneización (preservar el patrimonio urbano y perseguir la distinción barrial a partir de lo auténtico, exclusivo y original) de Caballito en los discursos de los vecinos organizados y no nucleados, a favor y en contra del centro comercial y de las torres? A partir de los relatos recogidos durante el trabajo de campo observamos que un mismo actor puede proceder desde distintas lógicas según las demandas coyunturales. De modo que el límite entre las posiciones que se alinean hacia la homogeneización o aquellas que lo hacen hacia la heterogeneización del barrio ${ }^{17}$ es impreciso. En los relatos de los vecinos encontramos que algunos están en contra del shopping pero a favor del complejo de viviendas Nuevo Caballito ${ }^{18}$. Otros están a favor del shopping sobre todo aquellos que viven en la vereda de enfrente al predio abandonado y esperan que pronto se revalorice la zona y, por lo tanto, sus propiedades con la llegada del centro comercial, pero también están a favor de la construcción de vivienda social en terrenos públicos. Algunos luchan por la preservación del patrimonio urbano e histórico como el Centro Cultural Estación de los Deseos y El Patio de Los Lecheros persiguiendo la distinción y el capital simbólico del barrio lo que implica una mirada elitista de la ciudad, pero también repudiaron los desalojos de 2008 de las acopiadoras de cartones y los recicladores urbanos que utilizaban los ex-terrenos ferroviarios como lugar de trabajo y se mostraron comprometidos con dicha problemática social. ${ }^{19}$

Muchos de los vecinos entrevistados son propietarios de sus viviendas y se encuentran de alguna manera involucrados en el juego inmobiliario y en la valorización de un capital propio. Según Oscar Yujnovsky (1974) la vivienda es mucho más que una unidad física individual. Implica también el flujo de servicios habitacionales proporcionados en un medio ambiente urbano determinado. Así, no sólo la forma, el tipo de vivienda y su condición edilicia aumentarían el valor de la propiedad; también influyen en su valorización los servicios a su alrededor como la

17 La heterogeneidad barrial no sólo incluiría la distinción de lo auténtico. También supondría una heterogeneidad social anclada en la convivencia de diversos sectores sociales. Aunque, como veremos a continuación, perseguir la distinción y elitización barrial generalmente conspira contra la inclusión y el acceso al barrio de los sectores bajos y medio-bajos de la sociedad.

${ }^{18}$ De hecho, una de las asociaciones vecinales participó del Concurso Nacional para urbanizar los ex-terrenos ferroviarios y obtuvo el segundo premio.

${ }^{19}$ Buena parte de estas ideas son tributarias de los debates que hemos tenido durante nuestras reuniones periódicas de investigación. En especial quiero agradecer a Joaquín Benitez por su aporte en el análisis de los procesos de homogeneización y heterogeneización ocurridos en el barrio de Caballito. 
recolección de residuos, el buen estado de las calles, el alumbrado público, los servicios de transporte, la accesibilidad a los servicios de salud y educativos, los espacios verdes y los comercios. Si bien el shopping y las torres en altura tienen un impacto negativo en Caballito, tal como lo describen los vecinos que están en contra de estos artefactos urbanos, también valorizan (sus) propiedades. Del mismo modo sucede con la lucha por los espacios verdes y la conservación del patrimonio urbano que llevan adelante muchas de las organizaciones barriales entrevistadas lo cual incide en la valorización de las propiedades y en el aumento del valor simbólico y la distinción del barrio. La apelación a la naturaleza por parte de estos vecinos "construye un rápido consenso sobre nuevos espacios públicos ofrecidos para todos, espacios que buscan aportar una emoción única al paseante en tanto celebran la excepcionalidad del patrimonio, la memoria o la naturaleza" (Carman, 2011: 169). En el barrio de Caballito los diversos factores descriptos que valorizan la propiedad terminan incidiendo en el aumento del precio del suelo, lo que a su vez impacta en un barrio cada vez menos accesible a sectores sociales con menor poder adquisitivo. ${ }^{20}$

\section{Menos cemento, más verde": reclamos y propuestas vecinales}

El barrio de Caballito posee una larga historia de reclamos realizados por los vecinos entre 2001 y 2008 en pos de establecer límites a un boom inmobiliario caracterizado por las torres en altura que venía operándose en la zona y que amenazaba con colapsar los servicios públicos. Esto se plasmó en una conquista por parte de los vecinos cuando la Legislatura de la Ciudad de Buenos Aires sancionó las leyes 2721/08 y 2722/08 limitando la altura posible de ser construida dentro de tres polígonos localizados en el barrio (Benitez, 2013). Estos antecedentes fueron los que hicieron posible el surgimiento de las asociaciones vecinales entrevistadas.

La organización vecinal Movimiento Identidad Caballito surge como continuación de la asociación Vecinos de Giordano Bruno fundada en 1997-1998 por un puñado de vecinas que se

\footnotetext{
${ }^{20}$ Es importante resaltar que tanto la valorización del suelo y de las propiedades como la distinción y elitización barrial no impulsan un proceso de gentrificación en Caballito. Generalmente la gentrificación se lleva a cabo en contextos de renovación urbana de áreas degradadas de la ciudad o abandonadas, como algunas zonas del sur de la ciudad (La Boca, San Telmo o Barracas), cuya principal consecuencia es la sustitución de la población residente de bajos ingresos que no puede acceder a los altos costos de las viviendas y los alquileres por población con mayor poder adquisitivo. Con este tipo de procesos se pretende cambiar el "perfil" de los habitantes de un barrio. En el imaginario social porteño así como en la propia identificación de los residentes, el barrio de Caballito es un "típico" barrio de clase media. A partir de la valorización de los inmuebles y de la búsqueda de distinción social y barrial se refuerza este imaginario. De modo que, como dijimos, Caballito se vuelve un barrio cada vez menos accesible a sectores sociales con bajo poder adquisitivo.
} 
manifestaron en contra de la construcción de un hipermercado: "(...) Se corría la bolilla de que ese terreno quería comprarlo Carrefour y ponernos un supermercado. Entonces, ahí dijimos 'no, nosotros queremos una placita para darle un uso público y verde' (...)"21. Años más tarde comenzaron a reclamar, junto a otras asociaciones vecinales y ONGs, por la mejora de los espacios verdes en el barrio de Caballito. Otra de las asociaciones vecinales con presencia en el barrio es Protocomuna Caballito, creada en 2003 por un grupo de vecinos que denunciaron la falta de cumplimiento del GCBA de las prioridades del "Presupuesto Participativo 2002". Poco a poco se fueron organizando con el objetivo de atender las demandas y preocupaciones de los vecinos: "en el año 2006/2007 entendimos que la principal problemática del barrio estaba dada por la sobreexplotación del recurso suelo en el barrio de Caballito. Un recurso estratégico que no es renovable, que tiene un punto en el cual ya no hay más, y nosotros entendíamos que se había superado un cierto punto de equilibrio"22. La tercera de las asociaciones entrevistadas es SOS Caballito que se constituyó en 2006 luego de una movilización vecinal que reunió a más de cincuenta personas para impedir la construcción de un edificio de diez pisos en una zona residencial de Caballito donde predominan las casas bajas. Los principios que rigen a esta asociación son "no a la construcción indiscriminada de edificios en altura, sí a la defensa de los espacios verdes (...), sí a la consulta comunal, popular y defensa del patrimonio urbano"23.

Estas organizaciones vecinales, junto a las asociaciones corporativas que nuclean a pequeños y medianos comerciantes se manifestaron y opusieron a la apertura del nuevo shopping bajo las consignas "IRSA no, parque sí" y "Menos cemento, más verde" 24 denunciando el carácter disruptivo que este tipo de emprendimientos tendría en el barrio y desplegando una campaña pública en su contra a través de diversos mecanismo de protestas colectivas y reclamos como cortes de calle en la vía pública, impresión de panfletos y afiches, cacerolazos, marchas hacia la Legislatura porteña, reuniones con comuneros y denuncias en los medios de comunicación (Imágenes 7 y 8). Según David Harvey, "los movimientos vecinales reclaman su reconocimiento y empoderamiento sobre la base del capital simbólico, y como resultado pueden afianzar su presencia política en la ciudad. Son sus bienes comunes urbanos los que son apropiados con demasiada frecuencia por los promotores inmobiliarios" (2013: 159).

\footnotetext{
${ }^{21}$ Miembro fundadora de Vecinos de Giordano Bruno y del Moviemiento Identidad Caballito.

22 Integrante de la Asociación Vecinal Protocomuna Caballito

23 Integrante de la Asociación Vecinal SOS Caballito.

${ }^{24}$ En la Ciudad de Buenos Aires el espacio verde es de 3,9 m2 por cada porteño. En el barrio de Caballito esta proporción apenas alcanza 1,9 m2 de espacio verde por habitante.
} 
Pedíamos la transferencia de la Nación de la totalidad de las tierras ferroviarias para que se rezonifiquen como Uso Parque. Ya en 2008 presentamos el rechazo absoluto a cualquier proyecto de construcción, ya sea un centro comercial o de torres (...) Nuestro reclamo es por el $100 \%$ de espacio verde. (Integrante de SOS Caballito).

Imagen 7. Panfleto convocando a manifestación vecinal, 04/12/2013
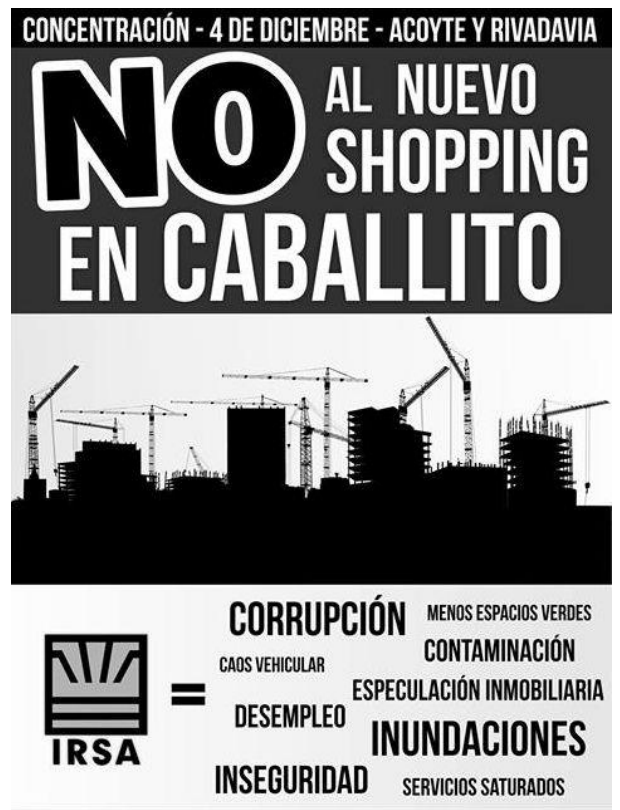

\section{VECINOS AUTOCONVOCADOS CONTRA EL SHOPPING}

Fuente: Imagen de archivo del colectivo "Encuentro en defensa del espacio público"

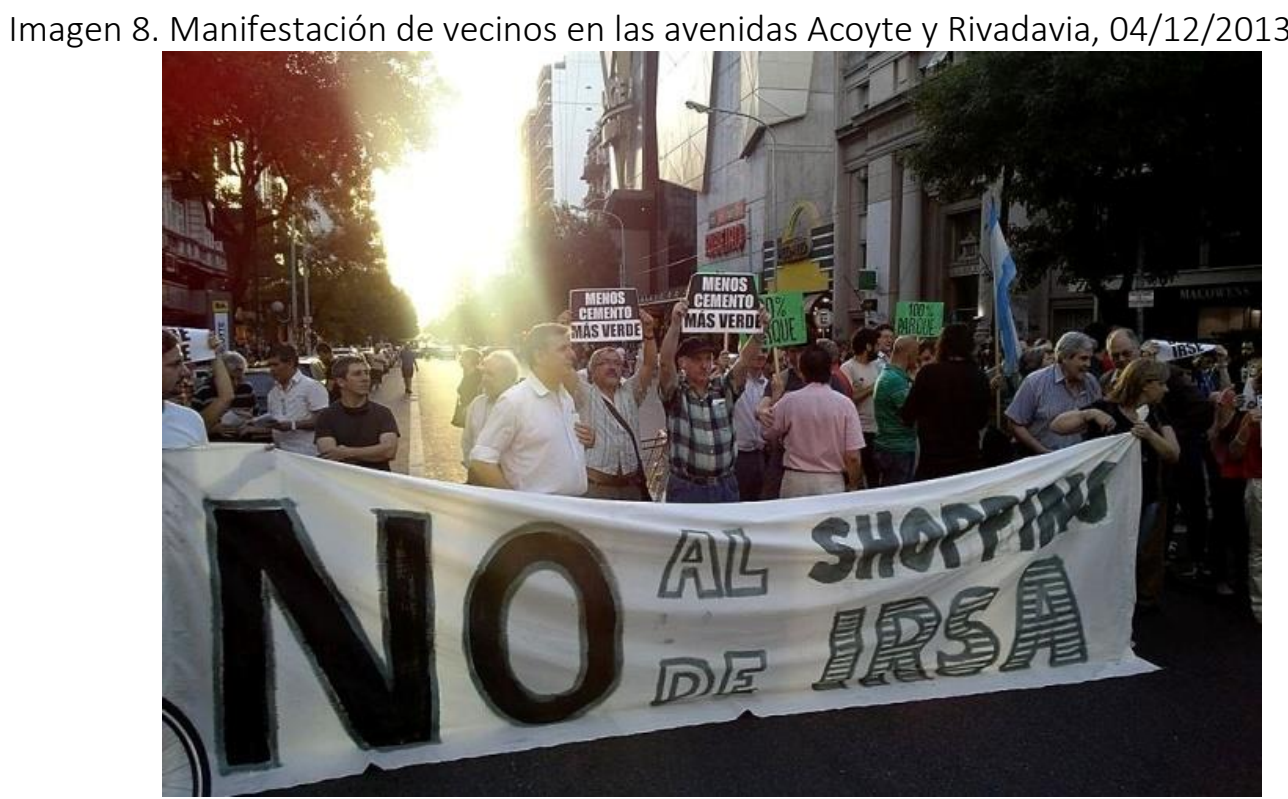

Fuente: Imagen de archivo del colectivo "Encuentro en defensa del espacio público" 
En agosto de 2014, luego de varios años de lucha y participación, el colectivo "Encuentro en defensa del espacio público" que nuclea a organizaciones vecinales y comerciantes de Caballito presentó la iniciativa vecinal Parque Caballito (Imagen 9) ante la Comuna 6 para llevarlo a cabo en las tierras que abarcan los ex-terrenos ferroviarios. El proyecto supone un plan alternativo a la construcción de viviendas y del shopping center e incluiría espacios verdes, escuelas públicas, una huerta orgánica, anfiteatros, centros culturales barriales y centros deportivos que se sumarían al ya existente Club Ferro Carril Oeste. Este proyecto busca mejorar la calidad de vida de los residentes del barrio y estimular el uso público del espacio por sobre el uso privado y especulativo, o en términos lefebvrianos, imponer los espacios de representación por sobre la representación del espacio.

Imagen 9. Plano del Proyecto Parque Caballito

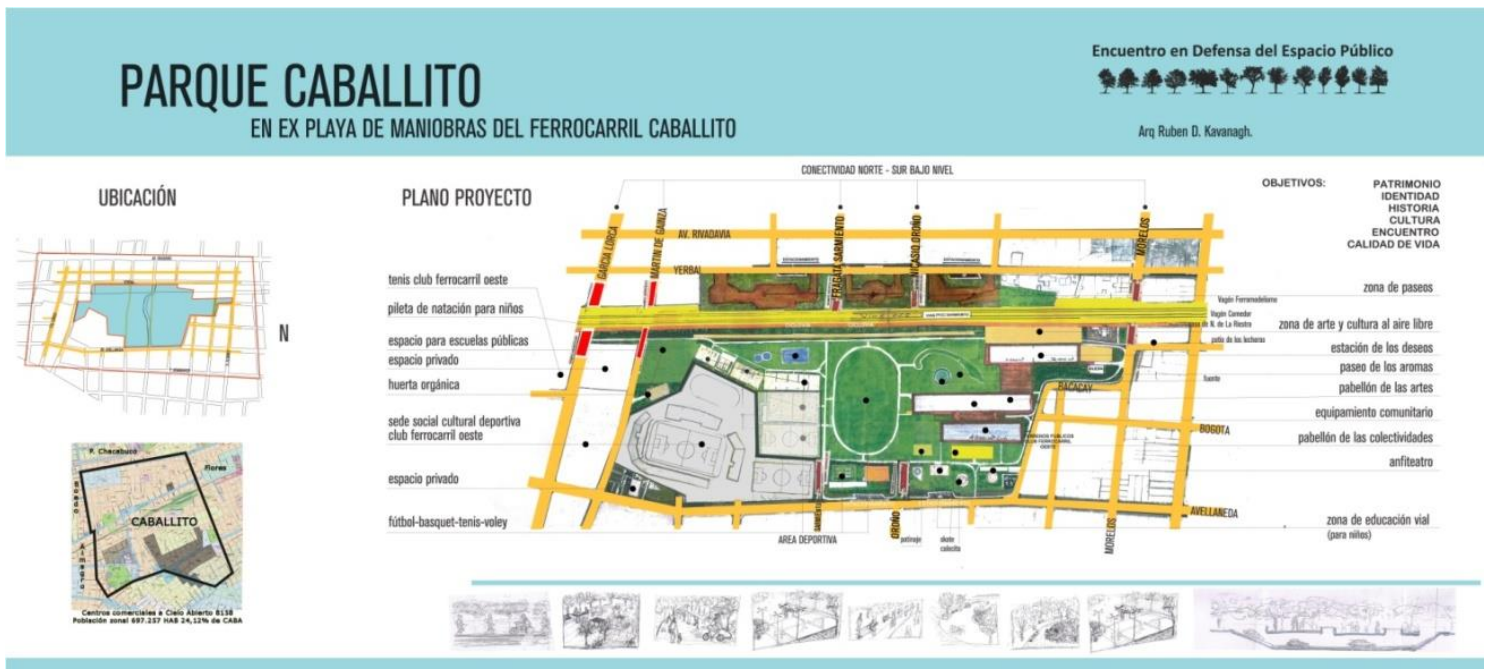

Fuente: www.nueva-ciudad.com.ar, consulta 10/02/2015.

Presentamos el Proyecto de Parque Caballito porque necesitamos más espacios verdes y públicos. El proyecto de parque incorpora un pulmón verde de casi 18 manzanas, con forestación nativa que servirá como espacio absorbente frente a las inundaciones, contará con zonas para las escuelas públicas del barrio y la educación ambiental y será un lugar de esparcimiento que podremos disfrutar todos los vecinos. (Integrante del colectivo "Encuentro en defensa del espacio público")

El espacio concebido de los ex-terrenos ferroviarios que por décadas se presentó y representó por las autoridades nacionales y locales y los emprendedores inmobiliarios como "espacios vacíos" en rigor se encontraban "llenos", colmados de compromisos, expectativas, 
propuestas y proyectos que los vecinos fueron articulando para el desarrollo de un parque público que permita mitigar tanto el déficit de espacios verdes que sufre el barrio como los procesos de impermeabilización del suelo que actualmente afectan a la ciudad (Benitez, 2013).

\section{PALABRAS FINALES}

Según David Harvey, las decisiones más importantes sobre la producción de las ciudades las toman las elites cuando deciden dónde se construye un shopping o dónde se edifica un emprendimiento inmobiliario. ${ }^{25}$ Para el geógrafo británico, hay un déficit de democracia urbana que sólo será remediado cuando los ciudadanos se unan y digan que todos tienen derecho a la ciudad, derecho a ser consultados para decidir y elegir en qué tipo de ciudad quieren/queremos vivir. Creemos que a través de la participación pública y de las asambleas consultivas y deliberativas entre todos los actores implicados en los procesos de transformación urbana es posible avanzar hacia una ciudad más justa e inclusiva y revertir la tendencia perversa y hegemónica de la mercantilización del espacio público. A partir de nuestro caso de estudio consideramos que existen manifestaciones de resistencia ciudadana a los procesos de mercantilización del suelo urbano que, aunque sean "espacialmente microscópicas" (Geertz, 1987), intentan producir ciudad a partir de otras lógicas urbanas.

Como vimos a lo largo de este trabajo, la lógica mercantil avanza sobre las lógicas sociales y culturales que se despliegan en el barrio de Caballito e incide en lo urbano, es decir, en la experiencia del espacio, los usos y las relaciones sociales que se entablan en el espacio urbano. En términos marxistas, los procesos de urbanización procurarán ajustar el valor de uso al valor de cambio. O en otras palabras, se intentará disolver lo urbano para transformarlo en urbanización (Delgado, 2003), y con ello se buscará disciplinar y regular el espacio percibido y vivido. Sin embargo, tanto en las resistencias y reacciones de las asociaciones vecinales y corporativas a la construcción del nuevo shopping y de las torres en altura, como en la propuesta de crear el Parque Caballito, entendemos que existen otras formas de "hacer ciudad" que se presentan como una alternativa a las lógicas hegemónicas de pensar, producir y construir la ciudad.

Es necesaria una intervención y regulación sobre el mercado del suelo para que la dinámica inmobiliaria no tienda a un proceso de valorización de todo el suelo de la ciudad. El "giro

25 Fuente: "Derecho a la ciudad dinámica", (Revista de Cultura Ñ, 09/02/2015) [http://www.revistaenie.clarin.com/ideas/David-Harvey-Derecho-ciudad-dinamica_0_1299470054.html], consulta: 12/02/15. 
emprendedor" del Estado (Franquesa, 2007), funcional a los intereses corporativos, financieros e inmobiliarios se traduce en una incapacidad, falta de voluntad política y complicidad con los grandes capitales para poner límites a la producción y valorización selectiva de la ciudad (Ciccolella y Mignaqui, 2008).

\section{REFERENCIAS BIBLIOGRÁFICAS}

BENITEZ, Joaquín. La centralidad en disputa: una aproximación al debate público sobre el futuro de los terrenos ferroviarios en la Ciudad de Buenos Aires. VII Jornadas de Jóvenes Investigadores del Instituto de Investigaciones Gino Germani, Ciudad Autónoma de Buenos Aires, 6-8 noviembre, 2013.

CARMAN, María. Las trampas de la naturaleza. Medio ambiente y segregación en Buenos Aires. Buenos Aires: CLACSO - Fondo de Cultura Económica, 2011.

CICCOLELLA, Pablo y MIGNAQUI, Iliana. Metrópolis latinoamericanas: fragilidad del Estado, proyecto hegemónico y demandas ciudadanas. Algunas reflexiones a partir del caso de Buenos Aires. Cuadernos del CENDES, año 25, n69, p. 47-68, 2008.

CUENYA, Beatriz. Grandes proyectos y sus impactos en la centralidad urbana. Cadernos Metropole, Brasil, n²5, p. 185-212, 2011.

DELGADO, Manuel. La no-ciudad como ciudad absoluta. Sileno, España, n 13, p.123-131, 2003.

El espacio público como falacia y representación en Lefebvre. XIV Congreso Arquine, Ciudad de México. 11-12 marzo, 2013.

FRANQUESA, Jaume. Vaciar y llenar, o la lógica espacial de la neoliberalización. REIS. Revista Española de Investigaciones Sociológicas, España, n 118, p. 123-150, 2007.

Urbanismo neoliberal, negocio inmobiliario y vida vecinal. El caso de Parma. Barcelona: ICARIA, 2013.

GEERTZ, Clifford. La interpretación de las culturas. Barcelona: Gedisa, 1987.

HARVEY, David. El neoliberalismo como destrucción creativa. Disponible en http://www.rebelion.org/noticia. php?id=65709, 2008 (Consulta: 10/08/2013).

Ciudades Rebeldes. Del derecho a la ciudad a la revolución urbana. Madrid: Akal, 2013.

LEFEBVRE, Henri. La producción del espacio. España: Capitán Swing, (2013) [1974].

MARCÚS, Juliana, AQUINO, P., BENITEZ, J., FELICE, M. y MARQUEZ, A. Procesos de vaciamiento y destrucción creativa en un barrio de la Ciudad de Buenos Aires. El caso de los ex-terrenos ferroviarios y los predios adyacentes. Revista AREA Agenda de reflexión en arquitectura, diseño y urbanismo, Buenos Aires, n²0, octubre, p. 74-85, 2014.

SCHUMPETER, Joseph. Capitalismo, socialismo y democracia. Madrid: Aguilar, 1962. 
SECRETARÍA DE PLANEAMIENTO. Construcción en la Ciudad de Buenos Aires, 2001-2011. Ministerio de Desarrollo Urbano, Ciudad de Buenos Aires, 2012.

SOCOLOFF, Ivana. Imágenes urbanas y escenas de un conflicto: aproximaciones al proyecto de Solares de Santa María, en Buenos Aires. Revista Questión, Buenos Aires, n 44, p. 358-372, 2014.

YUJNOVSKY, Oscar. Políticas de vivienda en la ciudad de Buenos Aires (1880-1914). Desarrollo Económico, Buenos Aires, vol. 14, n54, p. 327-372, 1974.

ZARLENGA, Matías y MARCÚS, Juliana. La cultura como estrategia de transformación urbana. Un análisis crítico de las ciudades de Barcelona y Buenos Aires. En M. MARGULIS et al., Intervenir en la cultura. Más allá de las políticas culturales, Buenos Aires: Editorial Biblos, p.33-55, 2014.

Trabalho enviado em 14 de agosto de 2015.

Aceito em 30 de setembro de 2015. 